\title{
OH column abundance over Table Mountain Facility, California: AM-PM diurnal asymmetry
}

\author{
King-Fai Li, ${ }^{1,2}$ Richard P. Cageao, ${ }^{3}$ Elliott M. Karpilovsky, ${ }^{1,4}$ Franklin P. Mills, ${ }^{3,5}$ \\ Yuk L. Yung, ${ }^{1}$ Jack S. Margolis, ${ }^{6}$ and Stanley P. Sander ${ }^{3}$ \\ Received 23 January 2005; revised 13 May 2005; accepted 23 May 2005; published 8 July 2005.
}

[1] Observations of the $\mathrm{OH}$ column abundance have been made by the Fourier Transform Ultraviolet Spectrometer at the JPL Table Mountain Facility (TMF) near Los Angeles since July 1997. In the January 1998December 2003 data set we used five $\mathrm{OH}$ lines to derive the $\mathrm{OH}$ column abundance in the atmosphere. This data set was used to quantify the $\mathrm{OH}$ morning/afternoon asymmetry (AMPMDA). An analysis of summer and winter data showed that the daily $\mathrm{OH}$ maximum occurred 26-36 minutes after solar transit. This phase lag appears to be the primary reason why $\mathrm{OH}$ in the afternoon is larger than at corresponding solar zenith angles in the morning throughout the year. A simple heuristic model suggests that the asymmetry is a direct consequence of the finite lifetime of $\mathrm{OH}$. Comparison of the TMF data with earlier results from Fritz Peak Observatory, Colorado, by Burnett et al. reveals significant differences in the behavior of the AMPMDA between the two sites. Citation: Li, K.-F., R. P. Cageao, E. M. Karpilovsky, F. P. Mills, Y. L. Yung, J. S. Margolis, and S. P. Sander (2005), OH column abundance over Table Mountain Facility, California: AM-PM diurnal asymmetry, Geophys. Res. Lett., 32, L13813, doi:10.1029/2005GL022521.

\section{Introduction}

[2] Progress in the study of the radiative and climatic impacts of ozone change requires a quantitative understanding of the formation and loss of ozone in all regions of the atmosphere. Long-term measurements using satellites, balloon sondes and ground-based instruments show two peaks in the vertical profile of ozone loss trends in the northern midlatitudes: one at $40 \mathrm{~km}$ with a value of about $-6 \%$ per decade and one at about $15 \mathrm{~km}$ with a value of about $-5 \%$ per decade [World Meteorological Organization, 2002]. While halogens are mainly responsible for the ozone loss trend at $40 \mathrm{~km}$, above this altitude the major catalytic loss terms are associated with the $\mathrm{HO}_{\mathrm{x}}$ family. Systematic, long-term measurements of

\footnotetext{
${ }^{1}$ Division of Geological and Planetary Sciences, California Institute of Technology, Pasadena, California, USA.

${ }^{2}$ Now at Department of Physics, Chinese University of Hong Kong, Shatin, New Territories, Hong Kong.

${ }^{3}$ Jet Propulsion Laboratory, California Institute of Technology, Pasadena, California, USA.

${ }^{4}$ Now at Department of Computer Science, Princeton University, Princeton, New Jersey, USA.

${ }^{5}$ Now at Centre for Resource and Environmental Studies, Australian National University, Canberra, A.C.T., Australia.

${ }^{6}$ Remote Sensing Analysis Systems, Altadena, California, USA.
}

$\mathrm{HO}_{\mathrm{x}}$ species therefore provide a useful tool for the analysis of ozone trends.

[3] Ground-based ultraviolet spectroscopy has been employed to measure the $\mathrm{OH}$ column abundance by observing $\mathrm{OH}$ absorption lines in the $\mathrm{A}^{2} \sum^{+} \leftarrow \mathrm{X}^{2} \prod(0,0)$ band at around $32400 \mathrm{~cm}^{-1}$ [Burnett and Burnett, 1981, 1983, 1984; Burnett et al., 1988; Cageao et al., 2001; Iwagami et al., 1995, 1998; Mills et al., 2002, 2003]. Burnett et al. [1988] noted that there is a morning/afternoon asymmetry in the diurnal cycle of the normalized $\mathrm{OH}$ column abundance, and called this effect the "AM-PM diurnal asymmetry (AMPMDA)". The authors analyzed the annual climatology of AMPMDA based on normalized data collected from 1978 to 1986 over the Fritz Peak Observatory $\left(40^{\circ} \mathrm{N}\right.$, $105^{\circ} \mathrm{W}$ ), Colorado (FPO) and from 1980 to 1986 over Boca Raton, Florida $\left(26.4^{\circ} \mathrm{N}, 80^{\circ} \mathrm{W}\right)$.

[4] Recently, an AMPMDA was reported for measurements of the $\mathrm{OH}$ column based on data collected from July 1997 to December 2001 over the Jet Propulsion Laboratory's Table Mountain Facility (TMF) $\left(34.4^{\circ} \mathrm{N}, 117.7^{\circ} \mathrm{W}\right)$ [Mills et al., 2003]. First-order fits of the column abundance vs. the solar zenith angle (SZA) showed a pronounced asymmetry with the $\mathrm{OH}$ formation rate in the morning being about $20 \%$ larger than the afternoon removal rate for almost all months using solar transit as a reference point. The results were obtained from retrievals that used the $\mathrm{P}_{1}(1)$ or $\mathrm{Q}_{1}(2)$ lines in the $\mathrm{OH}$ spectrum.

[5] Previous modeling studies have noted that $\mathrm{HO}_{\mathrm{x}}$ concentrations in the upper stratosphere and mesosphere should peak after solar noon [Prather, 1981]. Pickett and Peterson [1996] compared their balloon measurements of the $\mathrm{OH}$ vertical profile with the results of a steady-state model. They found that the average PM absolute abundance was larger than the average AM absolute abundance and suggested that the asymmetry could be explained by a 20-min phase lag in the photochemical reactions controlling $\mathrm{HO}_{\mathrm{x}}$ radicals. The AMPMDA has yet to be explained quantitatively with a fully coupled model constrained by realistic profiles of water vapor and ozone.

[6] This paper focuses on the observational evidence of the AMPMDA from the measurements made at TMF using the Fourier-Transform Ultraviolet Spectrometer (FTUVS) [Cageao et al., 2001]. Our goal was to include multiple $\mathrm{OH}$ absorption lines measured simultaneously in our retrieval so as to reduce the statistical uncertainty of the column measurement. We describe a method of analysis using five absorption lines to obtain a weighted average of the $\mathrm{OH}$ column abundance over TMF. The result is then used to examine the morning/afternoon diurnal cycle asymmetry in the $\mathrm{OH}$ column abundance. 
Table 1. Median Spectral Fit Uncertainty for The Five Selected OH Lines ${ }^{\mathrm{a}}$

\begin{tabular}{lccc}
\hline OH Line & Frequency, $\mathrm{cm}^{-1}$ & $\begin{array}{c}\text { Effective Absorption Cross Section, } \\
250 \mathrm{~K}, 10^{-16} \mathrm{~cm}^{2} \text { molecule }\end{array}$ & $\begin{array}{c}\text { Median Spectral Fit } \\
\text { Uncertainty, \% }\end{array}$ \\
\hline $\mathrm{P}_{1}(1)$ & 32440.5741 & 6.787 & 10 \\
$\mathrm{P}_{1}(2)$ & 32390.8857 & 5.660 & 11 \\
$\mathrm{Q}_{1}(2)$ & 32458.5918 & 7.530 & 13 \\
$\mathrm{Q}_{1}(3)$ & 32441.8175 & 5.633 & 14 \\
$\mathrm{P}_{1}(3)$ & 32340.5851 & 3.706 & 21 \\
\hline
\end{tabular}

${ }^{a}$ The lines are sorted in ascending order of the median spectral fit uncertainty. The line designations are described by Cageao et al. [1997]. Frequencies are from Stark et al. [1994]. Effective absorption cross sections are calculated using Einstein coefficients from Gillis et al. [2001], with equations from Dorn et al. [1995] assuming an effective temperature of $250 \mathrm{~K}$ and Doppler broadened line profiles. The distribution of the spectral fit uncertainty is similar to that found by Mills et al. [2003].

A simple heuristic model is employed to simulate the phenomenon.

\section{Observations}

[7] The FTUVS has been operated since 1997 under sky conditions which ranged from clear to hazy or partly cloudy. Observations have been made on 342 days from July 1997 through December 2003 and the total number of individual column observations numbered 9576 in this period. Each day in the summer (winter) has about 35-40 (23-27) $\mathrm{OH}$ column measurements. The FTUVS has a broad spectral coverage $\left(15600 \mathrm{~cm}^{-1}\right.$ to $\left.37000 \mathrm{~cm}^{-1}\right)$, high resolving power $(540,000)$ and a high signal-to-noise ratio (about 1700:1 for a 15-minute integration time). This permits observations of lines in the $\mathrm{OH} \mathrm{A}{ }^{2} \sum^{+} \leftarrow \mathrm{X}^{2} \prod(0,0)$ band that have a dynamic range of about a factor of 10 . The $\mathrm{OH}$ absorption lines observed by FTUVS are optically thin (a few per cent absorption, maximum) and hence the measurement is sensitive to the entire $\mathrm{OH}$ column.

[8] The reduction of data has been described previously [Cageao et al., 2001] and is summarized as follows: FTUVS alternately acquires spectra from the east and west solar limbs with an integration time of 15 minutes at each limb. Due to the rotation of the Sun, the east and west limb spectra are Doppler shifted with respect to one another while the telluric $\mathrm{OH}$ absorption lines remain fixed. By shifting and ratioing successive east-west spectral pairs, the Fraunhofer features are significantly attenuated. The resulting spectrum is fitted with a reference spectrum derived from a line-by-line forward model calculation that includes the instrument line shape function, Doppler-broadened $\mathrm{OH}$ line shape, and the same processing as the measured spectra. For $\mathrm{OH}$ column data derived from the $\mathrm{P}_{1}(1) \mathrm{OH}$ line alone, the systematic error, $2 \sigma_{s}$, is $\pm 12 \%$ and the random error, $2 \sigma_{r}$, is $\pm 14 \%$ [Cageao et al., 2001].

[9] More than twenty of the strongest $\mathrm{OH}$ absorption lines in the $A^{2} \sum \leftarrow X^{2} \prod(0,0)$ band have been identified in FTUVS solar spectra. Thirteen of these were selected for analysis based on visual inspection of the quality of the spectral fits. The selected lines were further examined to determine their respective spectral fit uncertainties in a large data set. The measurement error at each $\mathrm{OH}$ absorption line is taken as the square root of the variance in the residuals between the best spectral fit and the actual measurement, divided by the degrees of freedom. The uncertainty of the fit to each line in the spectrum is estimated from the measurement error by a parabolic expansion of $x^{2}$ around the $x^{2}$ minimization of the fit [Bevington and Robinson, 1992]. From a close inspection of the distribution of the spectral fit uncertainty, five absorption lines with relatively low median $\mathrm{OH}$ uncertainties were chosen for the present analysis. The line parameters and median spectral fit uncertainties are summarized in Table 1. Four of the five chosen $\mathrm{OH}$ lines are among the five lines with the largest effective peak cross sections. Although not in the latter group, the $\mathrm{P}_{1}(3)$ line was used in the average because it was relatively free from interference from residual solar lines.

\section{Results}

[10] Previous measurements of $\mathrm{OH}$ column abundances have used only the $\mathrm{P}_{1}(1)$ and $\mathrm{Q}_{1}(2)$ lines, which are among the strongest [Burnett et al., 1988; Iwagami et al., 1995,

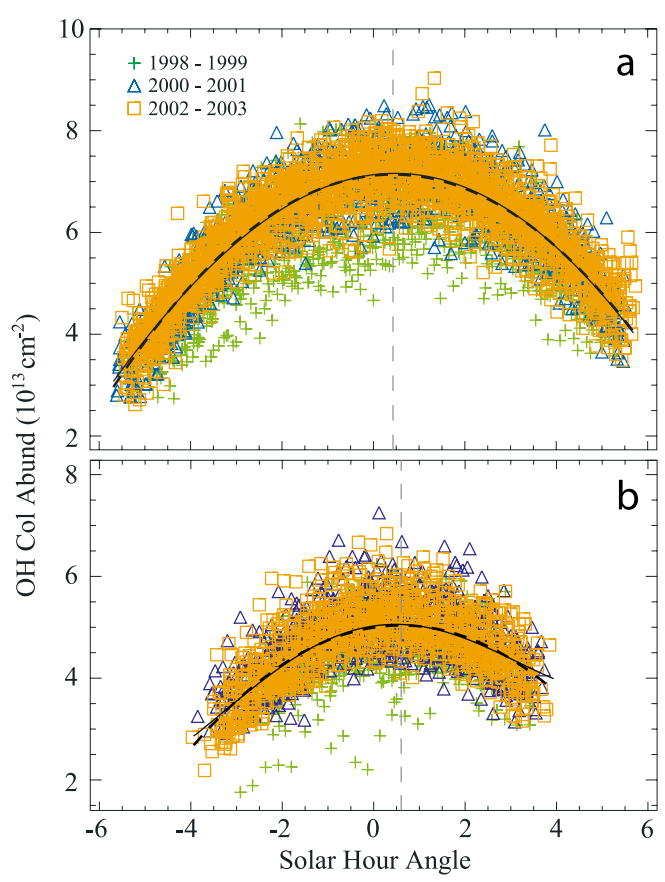

Figure 1. The diurnal cycle of $\mathrm{OH}$ column abundances obtained from the weighted average of five selected lines. (a) The data were collected in summers during Jan 1998 to Dec 2003. Each point represents an individual observation at the indicated solar hour angle. (b) Same as Figure 1a but with data collected in winters from Jan 1998 to Dec 2003. The second order fit (dashed) and the fourth order fit (solid) found by the means of least squares [Bevington and Robinson, 1992] are almost indistinguishable. The vertical line indicates the times at which the $\mathrm{OH}$ column abundance maximizes, given by $\mathrm{SHA}=b_{a v, s}$ in equation (2). 
Table 2. The Fitting Parameters for the 5-Line Average and $P_{1}(1)$ in Summer and Winter (Equation (1) $)^{\mathrm{a}}$

\begin{tabular}{lrrr}
\hline & $\mathrm{a}, 10^{12} \mathrm{~cm}^{-2}$ & $\mathrm{~b}, \mathrm{~min}$. & $\mathrm{c}, 10^{13} \mathrm{~cm}^{-2}$ \\
\hline \multicolumn{4}{c}{ 5-Line Average } \\
Summer & $-1.12 \pm 0.01$ & $26.0 \pm 0.7$ & $7.14 \pm 0.01$ \\
Winter & $-1.14 \pm 0.03$ & $36.0 \pm 1.8$ & $5.04 \pm 0.02$ \\
& \multicolumn{3}{c}{} \\
Summer & $-1.13 \pm 0.02$ & $P_{I}(1)$ & $28.0 \pm 1.4$ \\
Winter & $-1.19 \pm 0.06$ & $34.0 \pm 3.1$ & $7.05 \pm 0.03$ \\
\hline
\end{tabular}

${ }^{\mathrm{a}}$ Uncertainties are two standard deviations.

1998; Mills et al., 2002, 2003]. The $\mathrm{OH}$ columns derived from somewhat weaker lines may be used to increase the precision of the $\mathrm{OH}$ column measurements. To achieve this, the $\mathrm{OH}$ columns derived using the five selected absorption lines were averaged with appropriate weighting. For each day of measurement, the diurnal cycle for each absorption line was fitted with a second order polynomial, and the variance between the fit and the $i$ th absorption line, $\Delta[\mathrm{OH}]_{\mathrm{i}}$, was calculated [see, e.g., Graybill and Iyer, 1994]. The OH column abundance was calculated from an average of the five lines using $\left(\Delta[\mathrm{OH}]_{\mathrm{i}}\right)^{-1}$ as the weighting factor for each line.

[11] Figure 1a shows the retrieved data from the weighted average during May-August in 1998-2003 during which the daily minimum air mass varied from 1.02 to 1.2 (equivalent to the secant of SZA). The data are plotted against the solar hour angle (SHA) at the time that the spectra were acquired, expressed as the number of hours west $(+)$ or east $(-)$ of local celestial transit (due South).

[12] The diurnal variability of the $\mathrm{OH}$ column abundance was quantified by fitting the $\mathrm{OH}$ column vs. SHA with a second-order polynomial:

$$
[O H]=a(S H A-b)^{2}+c .
$$

Separate fits were carried out for both summer and winter and the second order diurnal fit parameters are shown in Table 2. As given by the parameter, $b$, the summer $[\mathrm{OH}]_{\mathrm{col}}$ maximum occurs $26.0 \pm 0.7$ minutes after solar transit. As a comparison, a fourth order polynomial fit is also shown in Figures $1 \mathrm{a}$ and $1 \mathrm{~b}$. The two fits are almost indistinguishable except near the end points implying higher order fits are unnecessary. A second order fit was also applied to the data collected during November-February in 1998-2003 (Figure 1b). During these months the daily minimum air mass varied from 1.3 to 1.9 at TMF. The second order fit coefficients for the winter data are given in Table 2 and the average daily $[\mathrm{OH}]_{\mathrm{col}}$ maximum occurs $36.0 \pm 1.8$ minutes after transit.

[13] The improvement in precision from the use of five $\mathrm{OH}$ lines in the weighted average can be seen by comparing with the results obtained using only the $\mathrm{P}_{1}(1)$ line. The second order fit parameters for summer and winter data of the $\mathrm{P}_{1}(1)$ line are shown in Table 2. The uncertainties from the 5-line weighted averages are a factor of about 1.75-2 smaller than those derived using the $\mathrm{P}_{1}(1)$ line alone.

\section{AM-PM Diurnal Asymmetry}

[14] In our analysis, the phase shift of the diurnal cycle is given by the polynomial fitting parameters $b_{a v, s}$ and $b_{a v, w}$ from equation (1). It has the same positive sign for both summer and winter, and lies between 26 and 36 minutes. This means that the maximum in the $\mathrm{OH}$ diurnal variation always lags $\mathrm{SHA}=0 \mathrm{hrs}$. and explains why the afternoon $\mathrm{OH}$ column is larger than the morning column [Mills et al., 2003]. The phase shift can be explained qualitatively by the lengthening of the $\mathrm{HO}_{\mathrm{x}}$ lifetime with increasing altitude in the stratosphere and lower mesosphere [Pickett and Peterson, 1996]. While a detailed analysis lies beyond the scope of this paper the average $\mathrm{HO}_{\mathrm{x}}$ time constant (which controls the diurnal variability of $\mathrm{OH}$ ) can be estimated using a linear response model with sinusoidal forcing [Camp et al., 2001]:

$$
\frac{d y(t)}{d t}=-\frac{y(t)}{\tau}+\frac{F(t)}{\tau} ; F(t)=A_{0} \sin \omega t,
$$

where $y(t)$ is the $\mathrm{OH}$ column abundance, $\tau$ is the $\mathrm{HO}_{\mathrm{x}}$ lifetime, and $F(t)$ is the photochemical source function of $\mathrm{HO}_{\mathrm{x}}$. The loss of $\mathrm{HO}_{\mathrm{x}}$ is non-linear so this is an approximate description. The source is assumed periodic with a frequency, $\omega$, approximately equal to one cycle per day. The response function $F(t)$ is divided by $\tau$ such that $A_{0}$ has the same dimension as $y(t)$. Equation (2) may be solved for $y(t)$ to obtain:

$$
y(t)=\left(y(0)+\frac{A_{0} \sin \phi}{\sqrt{1+\omega^{2} \tau^{2}}}\right) e^{-t / \tau}+\frac{A_{0} \sin (\omega t-\phi)}{\sqrt{1+\omega^{2} \tau^{2}}},
$$

where $y(0)$ is the value of $y$ at $t=0, \phi=\tan ^{-1}$ ( $\left.\omega \tau\right)$ for $0 \leq \phi \leq \pi / 2$. The phase shift, $b_{a v}$, obtained from the diurnal fit is related to $\tau$ by $b_{a v}=\phi / \omega=\omega^{-1} \tan ^{-1}(\omega \tau)$. Therefore the estimated column averaged lifetime of $\mathrm{HO}_{\mathrm{x}}$

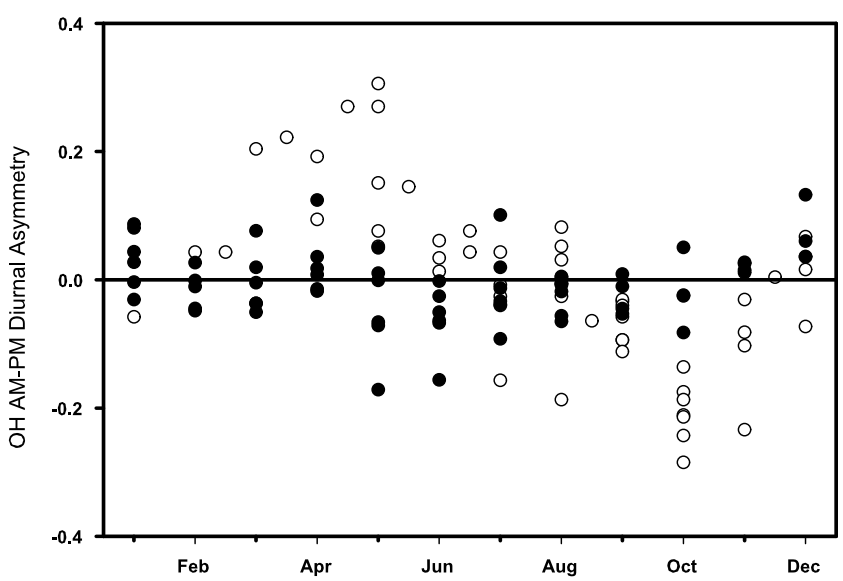

Figure 2. Comparison between $\mathrm{OH}$ column AMPMDA indices calculated from the FPO data of Burnett et al. [1988] from 1978 to 1986 (open circles) and the TMF data from 1998 through 2003 (filled circles). See text for definition of AMPMDA. The Burnett et al. data were normalized to the diurnal profile from a single year as described in the text. Over the nine-year record, their AMPMDA displays a mean offset of -0.07 . The offset has been subtracted from their data for better comparison with the TMF data, which has been normalized to the entire data set and therefore has a mean offset of zero. 
based on the measurements in summer and winter lies in the range

$$
\tau=\frac{1}{\omega} \tan \omega b_{a v} \approx 26-36 \min .
$$

[15] Burnett et al. [1988] calculated an AMPMDA index by subtracting the monthly average PM normalized abundance from the monthly average normalized AM abundance. The normalization used by Burnett et al. was the average of all data obtained from FPO between July 1981 and June 1982. To enhance the apparent asymmetry, data collected within an hour of local noon were not considered. The index calculated from the FPO data between 1978 and 1986 was consistent from year to year varying from about 0.2 in March to May to about -0.3 in October. The change in the sign of the index in their data indicates that there is a seasonal variation in the asymmetry relative to their normalized profile. In contrast, the asymmetry index, calculated from the TMF $\mathrm{OH}$ column data in the same manner, shows no consistent seasonal dependence. This is illustrated in Figure 2 which compares the AMPMDA index from FPO [Burnett et al., 1988] with the data from TMF. It is important to note that since AMPMDA is defined with respect to a normalized temporal profile which is itself asymmetric, a value of zero for AMPMDA does not mean that a given profile is symmetric; only that it matches the asymmetry of the reference profile. We conclude that there is a fundamental, unexplained discrepancy between the two data sets. This may be related to an instrumental artifact in one or both instruments, or to differences in dynamical forcing between the measurement sites that affect the transport of $\mathrm{OH}$ precursors, such as water vapor, to the stratosphere.

[16] Acknowledgments. This research was carried out by the Jet Propulsion Laboratory, California Institute of Technology, under contract with the National Aeronautics and Space Administration. KFL and EMK acknowledge support from the Caltech Summer Undergraduate Research Fellowship program. This work was supported by the NASA Upper Atmosphere Research Program (JPL), by NASA Grant NAG1-02081 (California Institute of Technology), and by the Australian Research Council (ANU)

\section{References}

Bevington, P. R., and D. K. Robinson (1992), Data Reduction and Error Analysis for the Physical Sciences, 2nd ed., McGraw-Hill, New York.

Burnett, C. R., and E. B. Burnett (1981), Spectroscopic measurements of the vertical column abundance of hydroxyl $(\mathrm{OH})$ in the Earth's atmosphere, J. Geophys. Res., 86, 5185-5202.

Burnett, C. R., and E. B. Burnett (1983), OH Pepsios, Appl. Opt, 9, $2887-$ 2892.

Burnett, C. R., and E. B. Burnett (1984), Observational results on the vertical column abundance of atmospheric hydroxyl-Description of its seasonal behavior 1977-1982 and of the 1982 El-Chichon perturbation, J. Geophys. Res., 89, 9603-9611.
Burnett, C. R., K. R. Minschwaner, and E. B. Burnett (1988), Vertical column abundance measurements of atmospheric hydroxyl from $26^{\circ} \mathrm{N}$, $40^{\circ} \mathrm{N}$, and $65^{\circ} \mathrm{N}$, J. Geophys. Res., 93, 5241-5253.

Cageao, R. P., Y. L. Ha, Y. Jiang, M. F. Morgan, Y. L. Yung, and S. P. Sander (1997), Calculated hydroxyl $\mathrm{A}^{2} \Sigma \rightarrow \mathrm{X}^{2} \prod$ band emission rate factors applicable to atmospheric spectroscopy, J Quant. Spectrosc. Radiat. Transfer, 57, 703-717.

Cageao, R. P., J.-F. Blavier, J. P. McGuire, Y. Jiang, V. Nemtchinov, F. P. Mills, and S. P. Sander (2001), High-resolution Fourier-transform ultraviolet-visible spectrometer for the measurement of atmospheric trace species: Application to OH, Appl. Opt., 40, 2024-2030.

Camp, D. D., M. S. Roulston, A. F. C. Haldemann, and Y. L. Yung (2001), The sensitivity of tropospheric methane to the interannual variability in tropospheric ozone, Chemosphere Global Change Sci., 3, 147-156.

Dorn, H. P., R. Neuroth, and A. Hofzumahaus (1995), Investigation of $\mathrm{OH}$ absorption cross-sections of rotational transitions in the a(2)Sigma(+), $\mathrm{V}^{\prime}=0-\mathrm{X}(2) \mathrm{Pi}, \mathrm{V}^{\prime \prime}=0$ band under atmospheric conditionsImplications for tropospheric long-path absorption-measurements, J. Geophys. Res., 100, 7397-7409.

Gillis, J. R., A. Goldman, G. Stark, and C. P. Rinsland (2001), Line parameters for the A(2)Sigma (+)-X-2 Pi bands of OH, J. Quant. Spectrosc. Radiat. Transfer, 68, 225-230.

Graybill, F. A., and H. Iyer (1994), Regression Analysis: Concepts and Applications, Wadsworth, Stamford, Conn.

Iwagami, N., S. Inomata, I. Murata, and T. Ogawa (1995), Doppler detection of hydroxyl column abundance in the middle atmosphere, J. Atmos. Chem., 20,1-15.

Iwagami, N., S. Inomata, I. Murata, and T. Ogawa (1998), Doppler detection of hydroxyl column abundance in the middle atmosphere: 2. Measurement for three years and comparison with a $1 \mathrm{D}$ model, J. Atmos. Chem., 29, 195-216.

Mills, F. P., R. P. Cageao, V. Nemtchinov, Y. Jiang, and S. P. Sander (2002), $\mathrm{OH}$ column abundance over Table Mountain Facility, California: Annual average 1997-2000, Geophys. Res. Lett., 29(15), 1742, doi:10.1029/ 2001 GL014151.

Mills, F. P., R. P. Cageao, S. P. Sander, M. Allen, Y. L. Yung, E. E. Remsberg, J. M. Russell III, and U. Richter (2003), OH column abundance over Table Mountain Facility, California: Intra-annual variations and comparisons to model predictions for 1997-2001, J. Geophys. Res., 108(D24), 4785, doi:10.1029/2003JD003481.

Pickett, H. M., and D. B. Peterson (1996), Comparison of measured stratospheric OH with prediction, J. Geophys. Res., 101, 16,789-16,796.

Prather, M. J. (1981), Ozone in the upper stratosphere and mesosphere, J. Geophys. Res., 86, 5325-5338.

Stark, G., J. W. Brault, and M. C. Abrams (1994), Fourier-transform spectra of the $\mathrm{A}^{2} \Sigma \leftarrow \mathrm{X}^{2} \prod(\Delta \nu=0)$ bands of $\mathrm{OH}$ and OD, J. Opt. Soc. Am. B Opt. Phys., 11, 3-32.

World Meteorological Organization (2002), Scientific Assessment of Ozone Depletion: 2002, Geneva.

R. P. Cageao and S. P. Sander, M/S 183-901, Jet Propulsion Laboratory, 4800 Oak Grove Drive, Pasadena, CA 91007, USA. (ssander@jpl.nasa. gov)

E. M. Karpilovsky, Department of Computer Science, Princeton University, Princeton, NJ 08544, USA.

K.-F. Li, Department of Physics, Chinese University of Hong Kong, Shatin, New Territories, Hong Kong.

J. S. Margolis, Remote Sensing Analysis Systems, Altadena, CA 91001, USA.

F. P. Mills, CRES, WK Hancock Bldg West, ANU, Canberra, ACT 0200, Australia.

Y. L. Yung, Division of Geological and Planetary Sciences, California Institute of Technology, MS 150-21, Pasadena, CA 91125, USA. 